\title{
ESTUDIO FENOTÍPICO COMPARATIVO DE CONSORCIOS MICROBIANOS CON ACTIVIDAD QUITINOLÍTICA DE SEDIMENTOS MARINOS Y RIZÓSFERA
}

\author{
COMPARATIVE PHENOTIPIC SURVEY OF MICROBIAL CONSORTIA WITH \\ CHITINOLYTIC ACTIVITY FROM MARINE SILTS AND RHIZOSPHERE
} Débora Alvarado, Lidia Flores, Ana María Guerrero, Zuleyka Vicente y Ruth García*

\section{RESUMEN}

Se colectaron 4 muestras de sedimentos tanto del fondo como de la orilla de la playa "Marbella", Callao y 4 muestras de tierra agricola a nivel de rizósfera obtenidas de un viñedo de la localidad de "Grocio Prado" en la Provincia de Chincha, Ica. Se determinó la densidad poblacional de microorganismos heterotróficos con actividad quitinolítica presentes en estos ambientes, y se describió sus principales características fenotípicas. Para la cuantificación de las poblaciones se empleó el método del Número Más Probable (NMP). Los tubos con crecimiento positivo fueron sembrados en placas con Agar Quitina Granulada y Agar Quitina Coloidal que fueron incubadas a temperatura ambiental hasta por dos semanas. Con las colonias desarrolladas se realizaron las pruebas de Oxidación/Fermentación de Glucosa, Oxidasa, Catalasa, motilidad, presencia de flagelo, capacidad tintoreal al GRAM, producción de esporas y actividad quitinolítica semicuantitativa. Se elaboraron fenogramas con el programa NTSYS V.1,7. La mayor densidad de bacterias quitinolíticas fue encontrada en la rizósfera alcanzando niveles $\geq 1,6 \times 10^{5}$ en tanto que en sedimentos marinos la densidad osciló entre $2,2 \times 10^{2}$ a 1,6 $\mathrm{x}$ $10^{4} \mathrm{NMP} / \mathrm{g}$. Luego del análisis de agrupamiento de los fenotipos mostrados por los consorcios estudiados, se encontró que presentaban caracteristicas distintivas, exhibiendo ambas una gran diversidad ienotípica.

Palabras clave: consorcios quitinolíticos, sedimento marino, rizósfera, microorganismos heterotróficos, fenograma.

\begin{abstract}
Four samples of silts were collected from the bottom and the bank of the beach "Marbella" in Callao and four samples of cultivated land were taken at level of thizosphere obtained from a vineyard of "Grocio Prado" Grassland's town in the Country of Chincha. The microbial heterotrophics populations with chitinolytic activity present in these environments was determined quantitatively, being described its main phenotypic characteristics. For the quantification of the populations the method of the Most Probable Number (NMP) was used. The tubes with positive growth were sowed in tubes with Granulated Chitin Agar and Colloidal Chitin Agar that were incubated at environmental temperature for two weeks. With the developed colonies the following tests were carried out: Oxidation/Fermentation of Glucose, Oxidase, Catalase, motility, presence of flagellum, tintoreal capacity, production of spores and semiquantitative chitinolytic activity. The phenograms were elaborated with the NTSYS v.1,7 program. The biggest density of chitinolytic bacteria was found in rhizosphere reaching levels of $\geq 1,6 \times 10^{5}$, as long as in marine silts the density oscillated among $2,2 \times 10^{2}$ to $1,6 \times 10^{4} \mathrm{NMP} / \mathrm{g}$. After the analysis of clustering of the phenotypes shown by the studied consortia it was found that they presented distinctive characteristic, exhibiting both of them a greal phenotypic diversity.
\end{abstract}

Key words: chitinolytic consortia, marine silt, hizosphere, helerotrophic microorganisms, phenogram.

*Lab. Microbiología Molecular. Fac. Cc. Biológicas, Univ. Nac. Mayor de San Marcos. Aptdo.720, Lima 1, Perú. E-mail, d190001@unmsm.edu.pe 


\section{INTRODUCCIÓN}

La quitina es uno de los biopolímeros más abundantes en la naturaleza, encontrándose principalmente en el ambiente marino donde forma parte del exoesqueleto de crustáceos y otros invertebrados (Gooday, 1998). Así mismo, en ambientes terrestres, se la encuentra conformando el isgumento de insectos y como constituyente primordial de la pared celular fúngica.

La molécula de quitina consiste en residuos de $\mathrm{N}$-acetil glucosamina unidos mediante enlaces b-1,4. Estos residuos están dispuestos en sentido antiparalelo (a), paralelo (b) o en ambos sentidos ( $g$ ), de las que la configuración a es la más abundante. La gran variedad de formas de quitina presentes en la naturaleza requiere de bacterias que tengan un gran número de diferentes quitinasas y otras enzimas degradadoras de quitina (Svitil et al., 1997; Sakai et al., 1998). Las enzimas quitinolíticas son generalmente inducidas como un complejo multienzimático y estín implicadas en la degradación de diversos residuos que contienen quitina (Leger el al., 1996; Carrillo \& Gómez, 1998).

De manera natural existen microorganismos con capacidad de producir enzimas que participan en los procesos de biodegradación de substratos orgánicos como la quitina. Estos microorganismos se encuentran tanto en ambientes acuáticos como terrestres (Yu, el al. 1991; Hunghming \& Mah, 1992; Boyer, 1994; Chernin et al., 1995; Svitil, 1997; Carrillo \& Gómcz, 1998). Vibrio harveyi y otras bacterias marinas pueden producir diferentes quitinasas en respuesta a la forma de quitina que encuentran en su ambiente, lo que implica su capacidad para distinguir diferentes tipos de quitina (Svitil et al., 1997).

Actualmente, el estudio de microorganismos quitinolíticos ha cobrado gran importancia e interés yá que ofrece una posibilidad potencial de aplicación en procesns de biorremediación, en ambientes donde la sobre explotación de los recursos naturales ha llevado a la acumulación de residuos hasta límites que exceden la capacidad de degradación propia de la naturaleza, así como la posible aplicación de estos microorganismos como biocontroladores de plagas agrícolas causadas principalmente por hongos e insectos debido a que llcvan quitina en sus estructuras (Skujins et al., 1965; Boyer, 1994; Chernin et al. 1995; Leger et al. 1996).

El presente trabajo tiene por objetivo la comparación de consorcios de microorganismos con actividad quitinolítica presentes en la rizósfera y sedimentos marinos, en relación a sus caracierísticas fenotípicas. Este estudio constituye una etapa inicial para la selección de estirpes microbianas productoras de enzimas con potencial uso en biotecnología (Shaikh \& Deshpande, 1993).

\section{MATERIAL Y MÉTODOS}

\section{Toma de muestra}

Se trabajó muestras procedentes de ambiente marino y de suelo cultivado.

Se colectaron 2 muestras de sedimento a nivel de orilla y 2 de fondo ( $4 \mathrm{~m}$ de profundidad) en la playa «Marbella», Callao, que fueron recogidas en frascos de vidrio estériles de $250 \mathrm{~mL}$ de capacidad con la ayuda de cucharas estériles y draga, respectivamente.

Las muestras de sutelo agrícola fueron colectadas a nivel de rizósfera en un viñedo de la localidad de "Grocio Prado" en Chincha, Ica. Las muestras se tomaron de 4 puntos diferentes y equidistantes $y$ fueron recogidas con cucharas estériles y colocadas en bolsas de primer uso.

Las muestras recogidas fueron transportadas en contenedores refiligerados.

\section{Recuento de microorganismos}

El recuento de microorganismos quitinolíticos fue realizado utilizando la técnica estadística del Número Más Probable 
(NMP) con una serie de 3 tubos, para lo cual se realizaron diluciones decimales en Solución Salina de hasta $10^{-4}$ para sedimentos marinos y $10^{-5}$ para las muestras de rizósfera siguiendo las recomendaciones de Dutka (1978) y APHA/AWWA/WPCF (1995).

El medio empleado para las muestras de origen marino fue el caldo Quitina Granulada (CQG), preparado con agua de mar (Boyer, 1994) y para las de rizósfera fue el caldo Quitina Coloidal (CQC) preparado con extracto de compost (Rodríguez-Kabana et al., 1983). Los tubos se incubaron a temperatura ambiente por 8 y 18 días para tierra de rizósfera y sedimentos marinos respectivamente. Los tubos que presentaron película y turbidez fueron considerados positivos en la lectura.

\section{Aislamiento de microorganismos quitinolíticos}

Los tubos positivos se sembraron por estriado en agar Quitina Granulada (AQG) y agar Quitina Coloidal (AQC) y las placas se incubaron a temperatura ambiente por 1 y 2 semanas para las muestras de rizósfera y sedimentos marinos respectivamente. Las colonias desarrolladas en los medios sólidos, fue- ron caracterizadas morfológicamente.

Para su conservación, las colonias en estudio fueron sembradas por puntura en viales con agar Luria semisólido y mantenidas a temperatura ambiente.

\section{Caracterización morfológica y fisiológica}

Se estudiaron 36 colonias provenientes de ambientes marinos y 31 de rizósfera, las cuales se reactivaron en caldo Luria por duplicado y se sembraron en medio Hugh y Leifson Glucosa (Oxidación/Fermentación) para determinar los tipos metabólicos. Fueron realizados también: coloración Gram, prueba de Motilidad en gota pendiente, coloración de flagelos por el método de Leifson (Leifson, 1951) y producción de esporas; se realizaron además las pruebas de Oxidasa y Catalasa.

\section{Actividad quitinolitica}

Los cultivos en Caldo Luria se sembraron por moteado sobre Agar Quitina Coloidal para muestras de rizósfera y agar Quitina Granulada para el caso de muestras de agua de mar, utilizando asa calibrada de $1 \mathrm{~mm}$ de diámetro. Las placas se incubaron a tempera-

Tabla 1. Recuento de microorganismos quitinolíticos presentes en rizósfera de vid y sedimento marino

\begin{tabular}{lc}
\hline \multicolumn{1}{c}{ MUESTRA } & $\begin{array}{c}\text { MICROORGANISMOS } \\
\text { QUITINOLITICOS } \\
\text { NMP/g }\end{array}$ \\
\hline RIZOSFERA & $\geq 16 \times 10^{4}$ \\
& $\geq 16 \times 10^{4}$ \\
& $\geq 16 \times 10^{4}$ \\
& $\geq 16 \times 10^{4}$ \\
& \\
SEDIMENTO & \\
MARINO & $16 \times 10^{3}$ \\
a. FONDO & $78 \times 10$ \\
A & $22 \times 10$ \\
B & $33 \times 10$ \\
b. ORILLA & \\
C & \\
D & \\
\hline
\end{tabular}


Tabla 2. Pruebas diferenciales básicas de las poblaciones quitinolíticas estudiadas

\begin{tabular}{|c|c|c|c|c|c|c|}
\hline \multirow{3}{*}{ PRUEBA } & \multirow{2}{*}{\multicolumn{2}{|c|}{ RIZÓSFERA }} & & & & \\
\hline & & & \multicolumn{2}{|c|}{ ORILLA } & \multicolumn{2}{|c|}{ FONDO } \\
\hline & $n=31$ & $\%$ & $n=13$ & $\%$ & $n=23$ & $\%$ \\
\hline $\begin{array}{l}\text { PRODUCCION DE } \\
\text { OXIDASA }\end{array}$ & 19 & 61,3 & 3 & 23,1 & 6 & 26,1 \\
\hline $\begin{array}{l}\text { PRODUCCION DE } \\
\text { CATALASA }\end{array}$ & 27 & 87,1 & 9 & 69,2 & 18 & 78,3 \\
\hline MÓVILES & 7 & 22,6 & 0 & 0,0 & 0 & 0,0 \\
\hline
\end{tabular}

tura ambiente por 9 días.

La actividad quitinolítica de las bacterias se evidenció por la formación de halos de digestión enzimática.

\section{Análisis estadístico}

Los resultados obtenidos fueron analizados utilizando el programa NTSYS v. 1.7 ("Numeral Taxonomy and Multivariate Análisis System"). Se elaboraron matrices empleando el Coeficiente de Similaridad Simple (SM) y los elementos de éstas fueron sometidos a análisis de agrupamientos con la técnica UPGMA ("Unweighted pair-group method using averages") para la elaboración de los fenogramas.

\section{RESULTADOS}

\section{Recuento de microorganismos y aislamiento}

Por medio de la técnica del NMP, se pudo comprobar que la mayor densidad de bacterias con capacidad quitinolítica se encuentra en las muestras procedentes de rizósfera. En los sedimentos marinos la mayor densidad de microorganismos quitinolíticos se ubicó en las muestras de fondo en comparación con las de

Tabla 3. Variedad morfológica de microorganismos quitinolíticos presentes en rizósfera y sedimento marino

\begin{tabular}{|c|c|c|c|c|c|c|c|}
\hline \multirow{3}{*}{\multicolumn{2}{|c|}{ TIPOS MORFOLÓGICOS }} & \multirow{2}{*}{\multicolumn{2}{|c|}{ RIZÓSFERA }} & \multicolumn{3}{|c|}{ SEDIMENTO MARINO } & \multirow[b]{3}{*}{$\%$} \\
\hline & & & & \multirow{2}{*}{ ORILLA } & \multicolumn{2}{|c|}{ FONDO } & \\
\hline & & $N=31$ & $\%$ & & $\%$ & $n=23$ & \\
\hline I & $\operatorname{Cocos} G(+)$ & 8 & 25,8 & 5 & 38,5 & 5 & 21,7 \\
\hline II & $\operatorname{Cocos} \mathrm{G}(-)$ & 1 & 3,2 & 1 & 7,7 & 0 & 0,0 \\
\hline III & Bacilos $G(+)$ & 11 & 35,5 & 2 & 15,4 & 12 & 52,2 \\
\hline IV & Bacilos G (-) & 0 & 0,0 & 3 & 23,1 & 2 & 8,7 \\
\hline $\mathrm{V}$ & Cocobacilos $\mathrm{G}(+)$ & 3 & 9,7 & I & 7,7 & 1 & 4,3 \\
\hline VI & Cocobacilos G $(-)$ & 4 & 12,9 & 1 & 7,7 & 1 & 4,3 \\
\hline VIl & Pleomórficos $\mathrm{G}(+)$ & 2 & 6,5 & 0 & 0,0 & 2 & 8,7 \\
\hline VIII & Pleomórficos G(-) & 2 & 6,5 & 0 & 0,0 & 0 & 0,0 \\
\hline
\end{tabular}


Tabla 4. Comportamiento de los microorganismos quitinolíticos en relación al metabolismo de la glucosa.

\begin{tabular}{|c|c|c|c|c|c|c|}
\hline \multirow{3}{*}{$\begin{array}{c}\text { METABOLISMO DE LA } \\
\text { GLUCOSA }\end{array}$} & \multicolumn{2}{|c|}{ RIZÓSFERA } & \multicolumn{4}{|c|}{ SEDIMENTO MARINO } \\
\hline & & & \multicolumn{2}{|l|}{ ORILLA } & \multicolumn{2}{|l|}{ FONDO } \\
\hline & $N=31$ & $\%$ & $\mathrm{n}=13$ & $\%$ & $n=23$ & $\%$ \\
\hline $\begin{array}{l}\text { No oxidadores no } \\
\text { fermentadores }\end{array}$ & 9 & 29,0 & 7 & 53,8 & 7 & 30,4 \\
\hline $\begin{array}{l}\text { Oxidadores no } \\
\text { fermentadores }\end{array}$ & 9 & 29,0 & 2 & 15,4 & 7 & 30,4 \\
\hline $\begin{array}{l}\text { Fermentadores } \\
\text { anaerogénicos }\end{array}$ & 6 & 19,4 & 1 & 7,7 & 0 & 0,0 \\
\hline Fermentadores aerogénicos & 7 & 22,6 & 0 & 0,0 & 0 & 0,0 \\
\hline No crecieron en medio $\mathrm{O} / \mathrm{F}$ & 0 & 0,0 & 3 & 23,1 & 9 & 39,2 \\
\hline
\end{tabular}

orilla (Tabla 1).

\section{Caracterización morfológica y}

\section{fisiológica}

Luego de realizar las pruebas diferenciales básicas de los consorcios quitinolíticos estudiados, se encontró que los microorganismos procedentes de rizósfera son predominantemente Oxidasa(+) y Catalasa(+), en cambio los organismos de sedimentos marinos son mayormente Oxidasa(-) y Catalasa (+). Las colonias aisladas de rizósfera en su mayoría son inmóviles $(87,4 \%)$, en cambio el $100 \%$ de los aislamientos provenientes de sedimentos marinos fueron inmóviles (Tabla 2). La coloración de Leifson confirmó la ausencia de estructuras flagelares en las cepas sin motilidad.

Al realizar la coloración Gram se encontró que las bacterias quitinolíticas estudiadas presentaban una gran variedad morfológica ( 8 tipos morfológicos). Los consorcios procedentes de rizósfera fueron en su mayoría bacilos Gram positivos $(35,5 \%)$. En cuanto a los microorganismos quitinolíticos procedentes de sedimentos marinos tenemos que: los que proceden de la orilla fueron en su mayoría cocos Gram positivos $(38,5 \%)$ y bacilos Gram

Tabla 5. Actividad quitinolítica de los microorganismos seleccionados en rizósfera y sedimento marino.

ACTIVID AD

QUITINOLITICA

(9 días de cultivo)

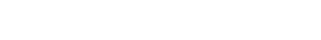

RIZÓSFERA

SEDIMENTO MARINO

\begin{tabular}{|c|c|c|c|c|c|c|}
\hline & $n=31$ & $\%$ & $n=13$ & $\%$ & $n=23$ & $\%$ \\
\hline Presencia de halo & 18 & 58,1 & 1 & 7,7 & 0 & 0,0 \\
\hline
\end{tabular}

Sin halo

1341,9

12

92,3

23

100.0 


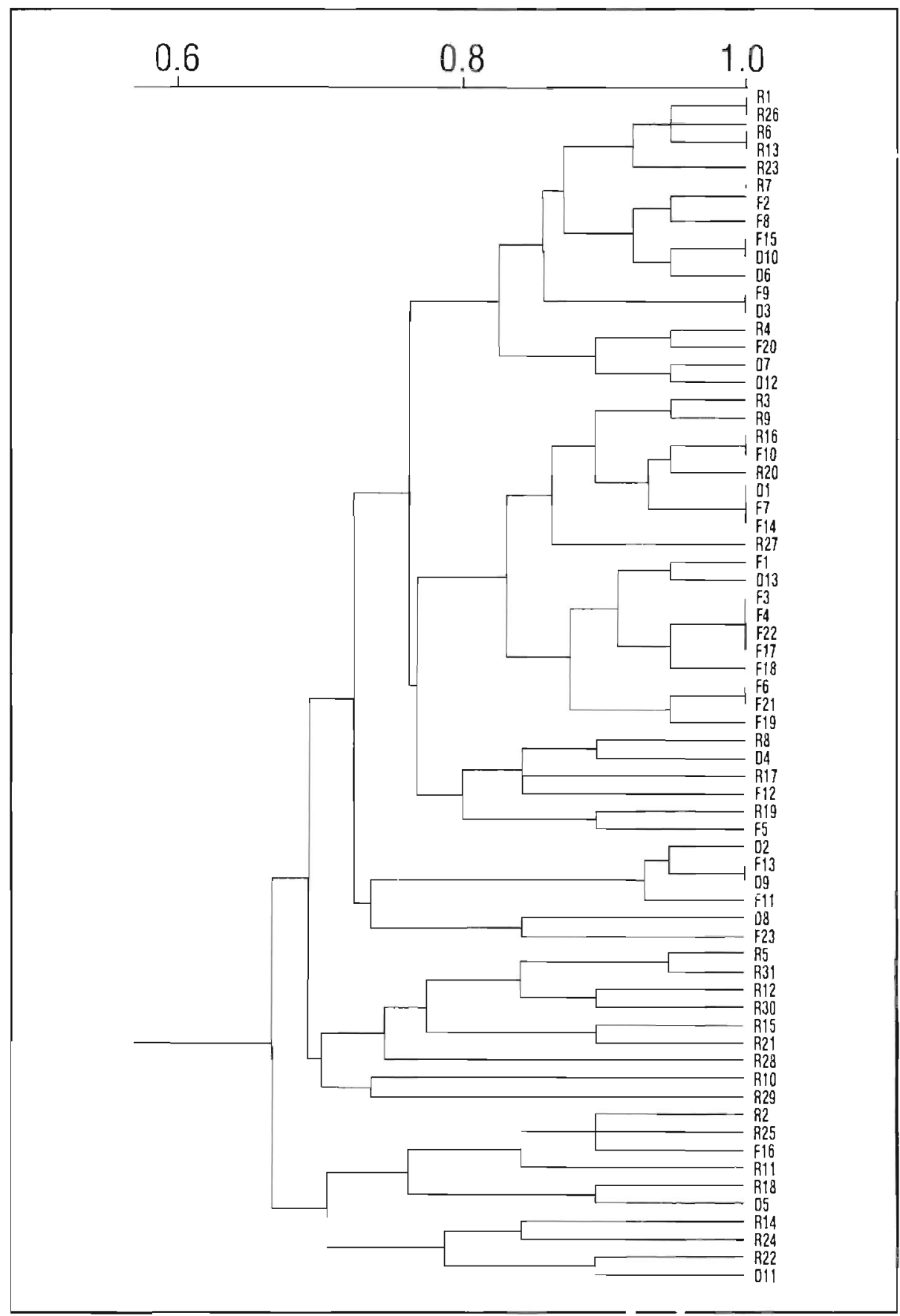

Figura 1. Fenograma construido utilizando coeficiente de sinilaridad de coincidencia simple y agrupamiento UPGMA para poblaciones microbianas quitinolíticas de rizósfera de vid (cepas R) y sedimentos marinos (cepas $O$ y F).

negativos $(23,1 \%)$, mientras que los microorganismos procedentes del fondo fueron predominantemente bacilos Gram positivos $(52,2 \%)$. Los aislados procedentes de rizósfera exhibieron la mayor diversidad de tipos morfológicos, un total de 7 (Tabla 3). No se encontraron organismos esporulados en ambos consorcios. 


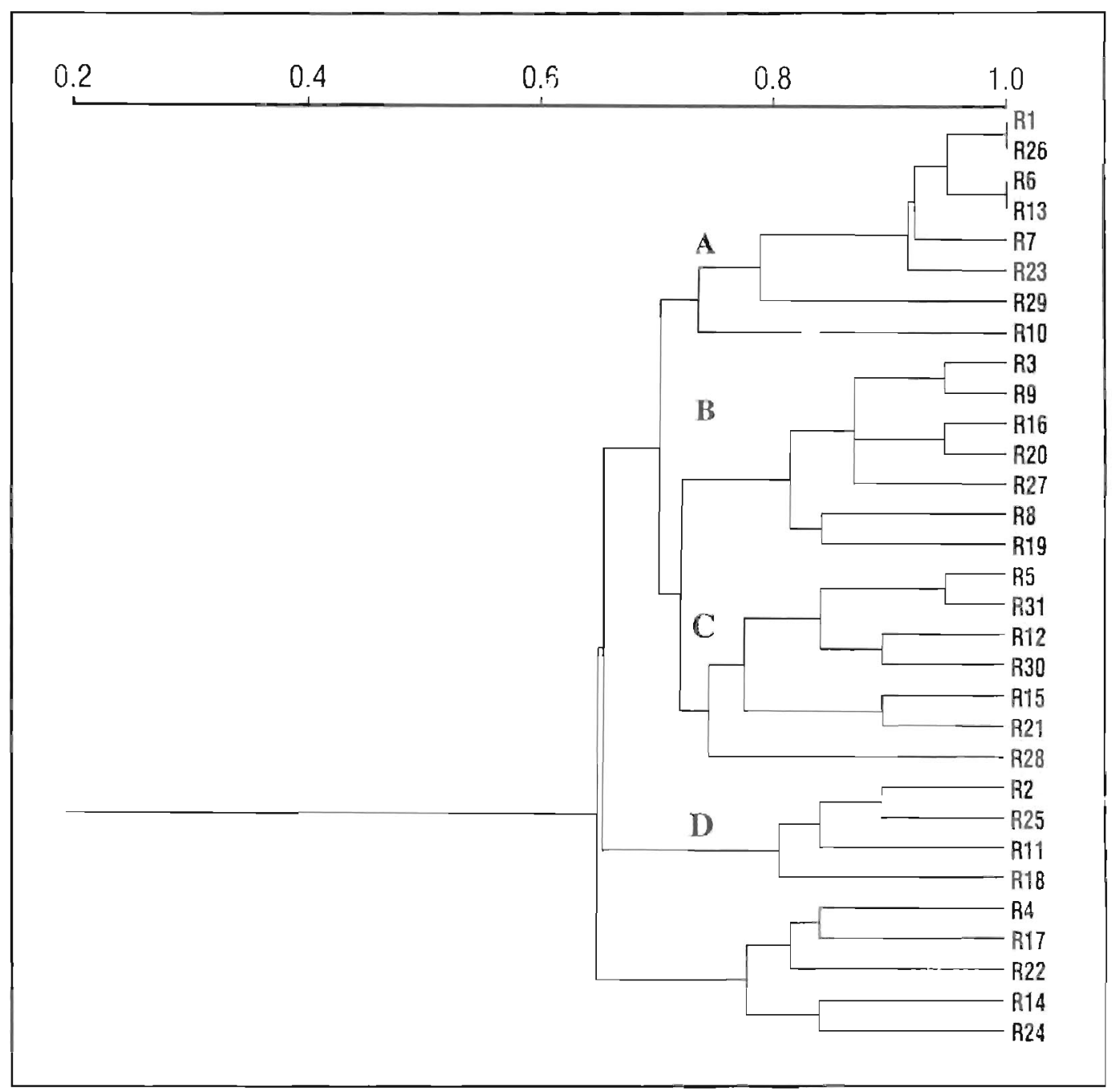

Figura 2. Fenograma construido utilizando el coeficiente de similaridad de coincidencia simple y agrupamiento UPGMA para poblaciones microbianas quitinolíticas de rizósfera de vid.

Al evaluar el comportamiento de los microorganismos quitinolíticos en relación con el metabolismo de la glucosa, encontramos que los microorganismos procedentes de fondos marinos no siguen vías fermentativas, mientras que sólo un $7,7 \%$ de los aislamientos de orilla son fermentadores anaerogénicos. El consorcio quitinolítico de rizósfera está conformado en un $58 \%$ por microorganismo; no fermentadores de glucosa (Tabla 4).

\section{Actividad quitinolítica}

A los 9 días de crecimiento se comparó 1 ? actividad quitinolítica entre los microorga- nismos procedentes de rizósfera y los procedentes de sedimentos marinos, encontrándose que los primeros presentaban una mayor actividad quitinolítica, que se evidenció por el rápido crecimiento de las colonias y lia formación de halos de digestión enzimática, mientra: que la mayoria de cepas aisladas de scdimentos marinos si bien crecieron, no formaron halo al cabo de ese tiempo (Tablis 5).

\section{Análisis de los consorcios}

El análisis de agrupamiento de lass características fenotípicas del total de aislaclos estudiados nos permite observar que tanto los 


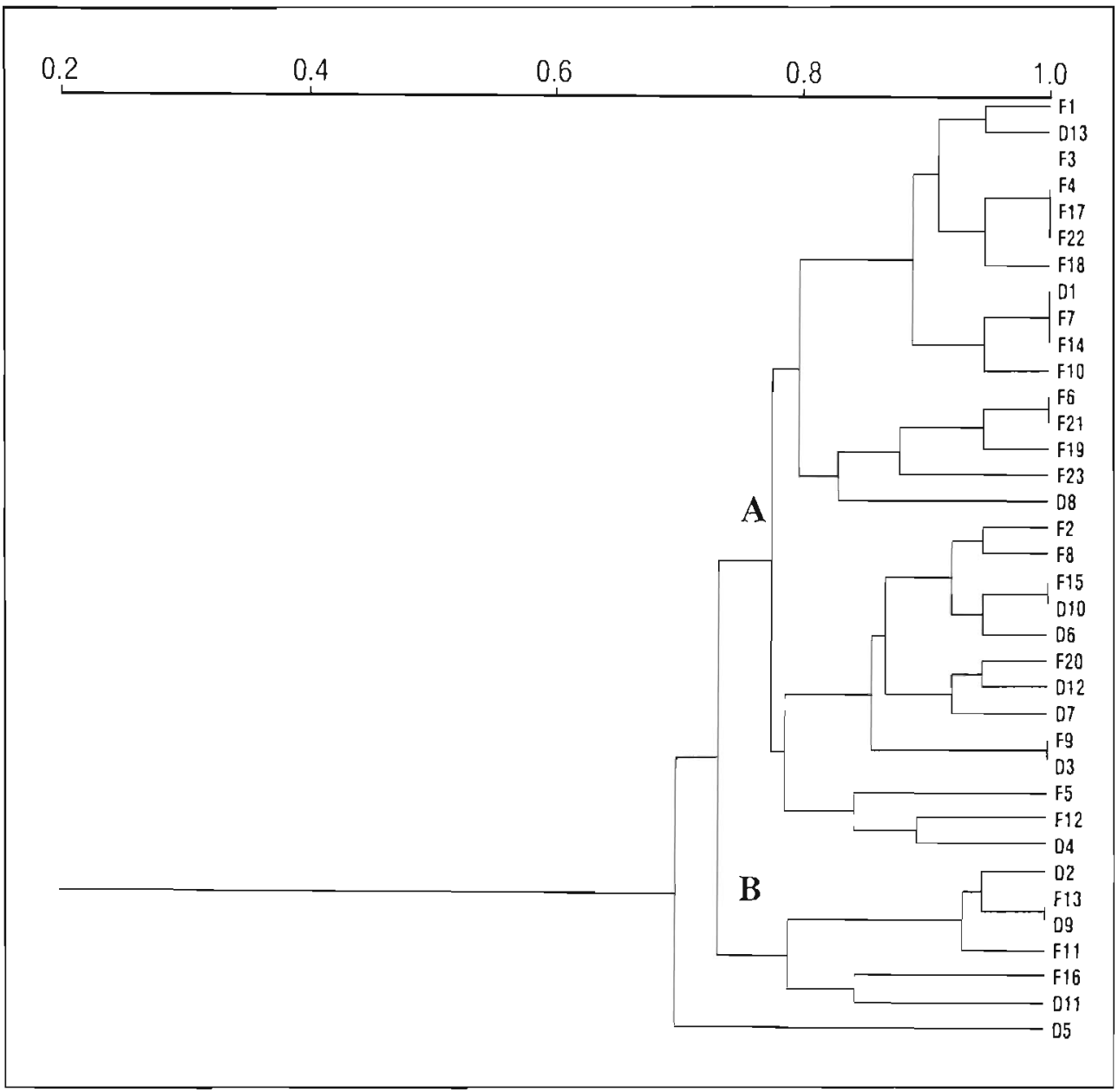

Figura 3. Fenograma construido utilizand o el coeficiente de similaridad de coincidencia simple y agrupamiento UPGMA para poblaciones microbianas quitinolíticas de sedimentos marinos.

consorcios microbianos de sedimentos marinos como de rizósfera tienen características comunes a un nivel de similaridad del 90\%; se distinguen, sin embargo, algunos grupos formados exclusivamente por organismos marinos o de rizósfera unidos a un nivel de similaridad inferior al $85 \%$ (Figura 1). Al analizar separadamente ambos consorcios (Figura 2 y Figura 3) podemos apreciar, a un nivel de similaridad del 75\%, 5 grupos en rizósfera y 2 en sedimentos marinos, lo que establece una mayor variedad fenotípica en los primeros. No se observan diferencias entre las poblaciones de orilla y sedimentos.

\section{DISCUSIÓN}

La densidad microbiana quitinolítica en rizósfera es 2 unidades logarítmicas mayor que la de fondos marinos, y 4 unidades mayor que la de sedimentos de orilla. Esto se podría explicar por el hecho di que las raíces de vid exudan sustancias nutritivas, principalmente azúcares, que permiten el incremento de microorganismos heterotróficos, especialmente hongos que poseen una pared celular a base de quitina la que a su vez ofrece un sustrato para bacterias quitinolíticas (Flach et al., 1992). 
Las difelencias encontradas en los consorcios de los dos ambientes en cuanto a su capacidad para la producción de la enzima Oxidasa, nos indicaría la disponibilidad en ambos ambientes de bacterias distinguibles y potencialmente utilizables para la biodegradación de la quitina. Las poblaciones estudiadas presentan escasa motilidad, 10 que nos permitiría suponer que estos organismos viven fundamentalmente adheridos a sus substratos.

Se observa un predominio de tipos morfológicu,s Gram (+), tanto en suelo como en mar, lo cual se explica por la facilidad que tienen éstos, un razón a la estructura de sus envolturas celulares, para liberar al medio extracelular enzimas líticas como las quitinasas. Se aprecia, además, una mayor diversidad de tipos morfológicos en rizósfera.

En cuanto a la actividad metabólica, los microorganismos quitinolíticos mayormente siguen vías oxidativas que son las que generan mayur cantidad de energía. En el caso de las poblaciones marinas se observa también un porcentaje considerable de individuos que no utilizan glucosa como principal fuente de carbono y energía, lo cual es comprensible si consideramos al medio ambiente marino como oligutrófico en comparación con el ambiente rizosférico (viñedos), que es un substrato rico en glucosa. Esta apreciación es reforzada por la lentitud con ia que las bacterias de ambientes marinos utilizan la quitina. La quitinolisis en el piso del océano es una actividad microbiana sumamente importante porque permite el mantenimiento de los niveles de C y $\mathrm{N}$ en el ecosistema marino (Yu et al., 1991).

Si bien los consorcios marinos y de rizósfera tienen características comunes en un nivel de similaridad bastante alto, considerando las pruebas incluidas en este trabajo, se pueden distinguir algunos grupos formados exclusivamente por organismos marinos y otros de rizósfera con una menor similitud, lo cual nos permite diferenciar microorganismos con características propias dentro de cada ecosistema. La mayor variabilidad fenotípica observada en el consorcio microbiano de rizósfera concuerda con las características de este ambiente descritas anteriormente.

La presencia de una gran diversidad fenotípica en consorcios microbianos quitinolíticos de ambientes terrestres y sedimentos marinos con características diferenciales justifica la exploración de estirpes productoras de enzimas en ambos ambientes, lo cual puede llevar a la selección y mejoramiento de cepas productoras de enzimas quitinolíticas, así como la utilización del material genético en la construcción biotecnológica de cepas que puedan utilizarse en procesos de biorremudiación y de control biológico de plagas.

\section{CONCLUSIONES}

Se encontró que en las condiciones de ensayo en el laboratorio, la mayor densidad de microorganismos quitinolíticos procede de las muestras de rizósfera de vid.

El consorcio quitinolítico de rizósfera es en su mayoría Oxidasa (+) y Catalasa (+), a diferencia del consorcio de sedimentos marinos que es mayormente Oxidasa (-) y Catalasa $(+)$.

Los consorcios quitinolíticos estudiados exhiben una gran diversidad morfológica.

El comportamiento de los microorganismos quitinolíticos de rizósfera y de sedimentos marinos en relación al metabolismo de la glucosa indica que la mayoria no sigue la vía fermentativa.

El análisis de agrupamiento de los consorcios, si bien nos muestra una alta similaridad entre fenotipos de sedimentos marinos y rizósfera en ambos ambientes, también permite determinar microorganismos con características fenotípicas propias en cada uno de los ecosistemas estudiados. 


\section{AGRADECIMIENTOS}

A la Biol. Rita Orozco Moreira del Inst. del Mar del Perú por su colaboración en la toma de muestras, así como al Dr. Abad Flores Paucarima por las facilidades brindadas para la realización del presente trabajo dentro del curso de Seminarios en Tópicos de Microbiología y Parasitología.

\section{LITERATURA CITADA}

APHA/AWWANWPCF. 1995. Standard methods for the examination of water and wastewater. $19^{\text {th }} \mathrm{Ed}$. American Public Health Association, Washington, D. C.

Boyer, J. 1994. Aerobic and anaerobic degradation and mineralization of $14 \mathrm{C}$-chitin by water column and sediment inocula of the York River Estuary, Virginia. Appl. Environ. Microbiol. 60(1): 174-9.

Carrillo, L. y M. Gómez. 1998. Producción de quitinasa por una cepa de Streplomyces griseoruter aislada de la rizósfera de la caña de azúcar. Rev. Arg. Microbiol. 30: 73-78.

Chernin, L. et al, 1995. Chitinolytic Enterobacter agglomerans antagonistic to fungal plant pathogens. Appl. Environ. Microbiol. 61(5): 1720-6.

Cottrell, M.; J. Moore \& D. Kirchman. 1999. Chitinases from uncultured marine microorganisms. Appl. Environ. Microbiol. 65(6): 2553-57.

Dutka, B. J. 1978. Methods for microbiological analysis of waters, wasterwater and sediments. Environmental Canada, 595 pp.

Flach, J.; P. E. Pilet \& P. Jolles. 1992. What's new in chitinase research? Experientia 48: 701-16.

Gooday, G. W. 1990. The ecology of chitin degradation. Adv. Microb. Ecol. 11: 387-430.
Hunghming, J. \& R. Mah. I 992. Isolation and characterization of Haloanaerobacter chitinovorans gen nov. sp, nov, a halophilic anaerobic, chitinolytic bacterium from a solar saltern. Appl. Environ. Microbiol. 58(1): 260-6.

Leger, R.; L. Joshi; M. Bidochka; N. Rizzo \& D.Roberts. 1996. Characterization and ultrastructural localization of chitinases from Melarhizium anisopliae, M. Flavoviride, and Beauveria bassiana during fungal invasion of host (Manduca sexra) cuticle. Appl. Environ. Microbiol. 62(3): $907-912$.

Leifson, E. 1951. Staining, shape and arrangement of bacterial flagella. J. Bacteriol. 62: 377-89.

Rodriguez-Kabana. R.; G. Godoy; G. Y. Morgan-Jones \& R.A.Shelby. 1983. The determination of soil chitinase activity: conditions for assay and ecological studies. Plant Soil 75: 95-106.

Sakai, K. et al. 1998. Purification and characterization of three thermostuble endochitinase of a noble Bacillus strain, M4-1, isolated from chitincontaining compost. Appl. Environ. Microbiol. 64(9): 3397-402.

Shaikh, S. \& Mi. Deshpande. 1993. Chitinolytic enzimes: their contribution to basic and applied research. World. J. Microbiol, Biotech. 9:468-75.

Skujins, J.: H. Potgieter \& M. Alexander. 1965. Dissolution of fungal cell walls by a Streptomycele chitinase and b(1@3) glucacase. Arch. Biochemistry Biophysics 111: 358-64.

Svitil, A. et al. 1997. Chitin degradation proteins produced by the marine bacterium, Alteromonas sp. suain $\mathrm{O}-7$, and its corresponding gene and domain structure. Appl. Environ. ivicrobiol. 63(2): 408-13.

Yu, C.; A. M. Lee; B. L. Bassier \& S. Roseman. 1991. Chitin utilization by marine bacteria. J. Biol. Chem. 266: 24260-6. 